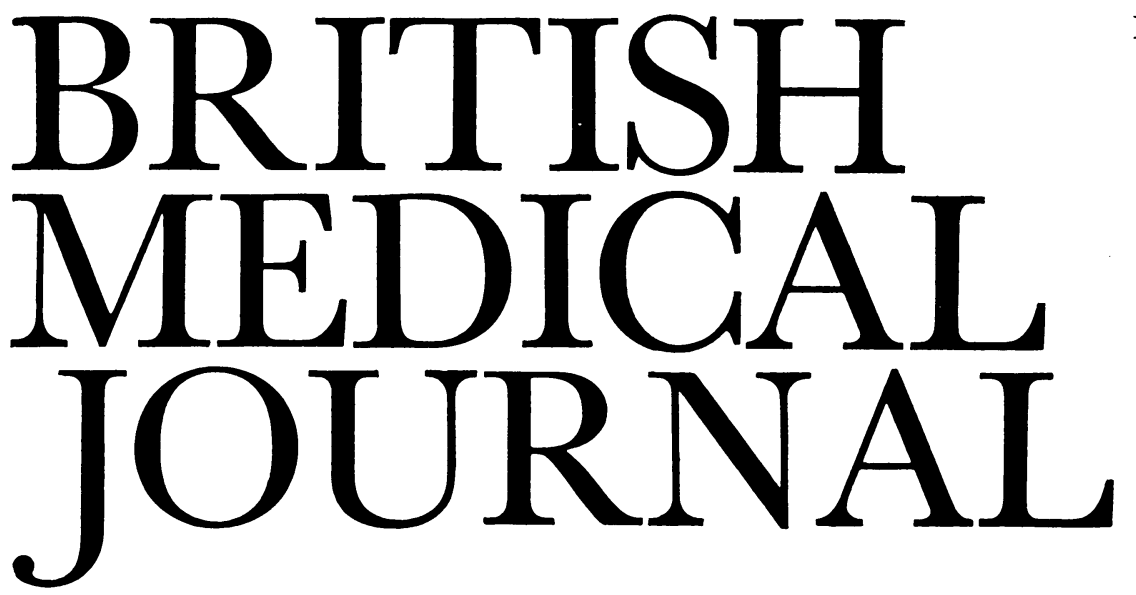

LONDON, SATURDAY 5 DECEMBER 1981

\title{
Reform of mental health legislation
}

The long-awaited Bill to amend the Mental Health Act (1959) was published very rapidly after the Queen's Speech, together with yet another White Paper. ${ }^{1}$ The revolutionary Mental Treatment Act of 1930 followed the Royal Commission report of $1926^{2}$ and the liberal Mental Health Act of 1959 followed another Royal Commission (the Percy Commission) report of 1957. ${ }^{3}$ This new Bill follows a different process. True, it was partly stimulated by the Butler Committee's inquiry into the problems of the mentally abnormal offender, ${ }^{4}$ but a good deal of the impetus has been provided by two influential books published by the National Association for Mental Health (MIND) and written by its American lawyer, Larry Gostin. ${ }^{5}$ Subsequent public and professional debate has been focused by a Labour Government Green Paper $^{7}$ and White Paper. ${ }^{8}$

It is a great tribute to the 1959 Act that a fairly intensive $\mathrm{d}$ bate over seven or eight years has produced only a modest list of proposed changes. These are:

Halving the period before the compulsory detention of any patient (except those on restriction orders) has to be either renewed or ended.

Psychopaths and subnormals (now to be renamed as mentally handicapped) are to be allowed to be detained only if they are thought treatable. In contrast, the age limit protections for such patients under the civil procedures in the Act are to be removed.

Access to Mental Health Review Tribunals is to be doubled.

Local authorities are to approve social workers as mental welfare officers.

Emergency admission procedures are to be tightened up and nurses are to have the power to detain an informal patient for six hours.

A multiprofessional Mental Health Act Commission is to be established to provide a general protective function for all detained patients. The commission will visit all psychiatric hospitals once or twice a year and each special hospital once a month. The commission will also lay down guidelines about the giving of compulsory treatments to detained patients.

Three groups of treatment for mental disorder are to be established: (a) treatments of special concern which may be given only with the patient's consent and the agreement of an independent doctor; $(b)$ treatments which may be given without the patient's consent but must have the agreement of an independent doctor; and (c) other treatments which may be given without the patient's consent at the discretion of the responsible doctor. Which treatments are to be which is not yet clear, however, and will be determined by ministerial regulations and an advisory code of practice drawn up by the Mental Health Act Commission.

Guardianship is to be much more limited in its scope, simply giving the guardian (usually a local authority) the three essential powers of determining where a patient shall live. that he shall have treatment, and that he may be visited at home.

Restriction orders are to be applied to offender patients only "for the protection of the public from serious harm."

Remands to hospital will become possible for medical reports, treatments, and assessment. Interim hospital orders for up to six months are to be introduced, and prisoners transferred to hospital are to become unrestricted at their earliest date of release instead of at the end of their nominal sentence as at present.

Widespread consultation has meant that few of the measures are likely to be contentious. The major difference between this White Paper and the one from the Labour Government is the proposal for a Mental Health Act Commission. This is an important achievement for the Royal College of Psychiatrists and for the Boynton Committee, ${ }^{9}$ which recommended it. The commission will probably be sufficiently independent and multidisciplinary to be acceptable to the lobby which wants all compulsory treatment monitored by multidisciplinary panels. Curiously, no one has come up with a formula for compulsory treatment that properly mirrors the ordinary consenting procedure in medical practice. The first steps to medical consent are medical-making the diagnosis, choosing the appropriate treatment, getting other opinions, and so on. The second is lay, the patient deciding for himself, in the light of the medical advice, whether or not to accept a particular treatment. This lay element is not covered by multidisciplinary teams, or by the new Bill. A recent working party of the Council for Science and Society ${ }^{10}$ had a stab at tackling the problem and concluded: "The best long-term guarantee of safeguards lies in confining them to independent members of independent health professions, neither individually or collectively subject to direction ... by potentially authoritarian state institutions and reinforced by codes of professional ethics, and ultimately by the law." Let us hope that the new Mental Health Act Commission will not become an "authoritarian state institution" but become instead a trend setter of ethical standards by professional discussion and perhaps medical audit.

At first sight the new commission looks like the old Board 
of Control, but in fact it is to limit its activities to the care and treatment of detained patients leaving the Hospital Advisory Service to continue with monitoring hospital facilities in general. This is a pity, for the Hospital Advisory Service has failed to keep psychiatric hospitals up to standard. To take a recent example, the Royal College of Psychiatrists has just reported" "on the disgracefully low standards for ECT clinics which exist in some hospitals," yet the vast majority of patients having electroconvulsive therapy are there through informal admission, outside the purview of the new commission. We can only hope that the commission, by examining standards of care for detained patients, will be able to improve facilities for all patients.

Perhaps the biggest anxiety for psychiatrists is the uncertainty about which treatments will fall into which category of control. No doubt these questions need to be determined flexibly in the light of changing knowledge, but that policy may mean that there will be lobbying from time to time (especially after the passage of the Bill) to ensure that a particular treatment gets a particular grading.

A curiously illiberal proposed change is the Government's determination to drop the age qualification for the compulsory detention of psychopathic and subnormal people. At present such people cannot be put on an order unless they are under 21 or have committed a criminal offence. This is to protect citizens who become a nuisance from indefinite confinement in hospital at the whim of two doctors and a relative unless they are severely subnormal or mentally ill. The Bill proposes that psychopaths and subnormals will be eligible for compulsory detention, whatever their age, provided they are "treatable"-a proposal that would warm the cockles of the heart of a dictator having trouble with dissidents. Presumably the assumption is that Britain is a democracy and that, as in practice no psychiatrist here would wish to put an unwilling psychopath or subnormal on an order, and that as "treatability" would have to be claimed anyway, this safeguard so carefully inserted by Parliament in the current legislation may be dropped. Nevertheless it does seem an unnecessarily backward step in a liberalising Bill.

The resource implications of some of these measures are briefly touched on in the White Paper. The number of tribunal hearings is expected to rise from 904 in 1980 to around 4500 a year, a matter said to be of "no great cost"! More realistically, remands to hospitals and interim hospital orders are expected to cost extra. These arrangements are planned to come into operation "two or three years after the Bill is passed to allow the extra manpower and new buildings to be provided." That could mean that the recommendations will become entirely theoretical. Perhaps it is idle speculation and too late anyway to suggest that the real deficiencies in our mental health services are resources not laws and that more money would solve most of the problems; without funds these legal proposals will not have much impact.

One outstanding illiberality of the 1959 legislation remains to be tackled. Britain has a system whereby every mentally abnormal offender admitted to hospital whom the court considers to be a risk to the public may be put on an indefinite restriction order, to be released only at the unchallenged discretion of the Home Secretary. The European Court of Human Rights has recently ruled that this system is wrong and that the Home Secretary's decisions should be subject to appeal in a court. The White Paper notes the point, saying that the Government will decide what to do after it has had time to study the judgment. Neither the European Court nor this White Paper comments on whether it is right to put offenders who have committed offences other than murder on such an indefinite restriction order in the first place.

Professor of Forensic Psychiatry,

JoHN GuNN

Institute of Psychiatry,

London SE5 8AF

1 Department of Health and Social Security, Home Office, Welsh Office, Lord Chancellor's Department. Reform of mental health legislation. London: HMSO, 1981. (Cmnd 8405.)

- Royal Commission on Lunacy and Mental Disorder. Report. London: HMSO, 1926. (Cmnd 2700.)

${ }^{3}$ Royal Commission on the Law Relating to Mental Illness and Menta Deficiency. Report. 1954-1957. London: HMSO, 1957. (Cmnd 169.)

+ Home Office, Department of Health and Social Security. Report of the Committee on Mentally Abnormal Offenders. London: HMSO, 1975. (Cmnd 6244.)

${ }^{5}$ Gostin LO. A human condition, the Mental Health Act from 1959 to 1975 Volume 1. Leeds: National Association for Mental Health, 1975.

${ }^{6}$ Gostin LO. A human condition. The law relating to mentally abnormal offenders. Observations, analysis and proposals for reform. Volume 2. London: MIND (National Association for Mental Health), 1977.

'Department of Health and Social Security. A review of the Mental Health Act 1959. London: HMSO, 1976.

${ }^{8}$ Department of Health and Social Security, Home Office, Welsh Office, Lord Chancellor's Department. Review of the Mental Health Act 1959 London: HMSO, 1978. (Cmnd 7320.)

${ }^{9}$ Department of Health and Social Security. Report of the review of Rampton Hospital. London: HMSO, 1980. (Cmnd 8073.)

10 Council for Science and Society. Treating the troublesome. Report of a working party. London: Council for Science and Society, 1981.

11 Pippard J, Ellam L. Electroconvulsive treatment in Great Britain, 1980. London: Gaskell, 1981.

\section{Milwaukee shoulder}

Chronic tophaceous gout is not so common as it used to be. When it does occur, however, the deposits of urate crystals in connective tissue are often accompanied by a chronic destructive arthritis and large defects in bone and cartilage. ${ }^{1}$ Calcium pyrophosphate dihydrate crystals in articular cartilage (chondrocalcinosis), usually in the knee joint, are a common finding in elderly people. ${ }^{2}$ Some patients also develop a chronic destructive arthritis (chronic pyrophosphate arthropathy) as well as having acute, self-limiting attacks of synovitis (pseudogout). ${ }^{34} \mathrm{~A}$ rapidly progressive form of destructive arthritis has also been described in patients who show pyrophosphate crystals; and there may be clinical and radiological findings similar to those seen in Charcot joints ("pseudoneurotrophic arthritis"). ${ }^{56}$ Recently a third type of crystal, hydroxyapatite, has been associated with chronic joint damage, deposits being found in the articular cartilage and synovial fluid of some patients with osteoarthritis. ${ }^{78}$ These hydroxyapatite crystals may be present in the more severe forms of osteoarthritis, ${ }^{9}$ and advanced destructive changes have been seen in cases of mixed pyrophosphate and hydroxyapatite deposition. ${ }^{10}$

This association between crystal deposition and chronic destructive joint disease has never been adequately explained. A "chicken-and-egg" argument arises: Do the crystals cause the damage or does joint destruction predispose to crystal formation? There is evidence for both, and a vicious cycle of joint damage, crystal growth, and further joint damage has been postulated. ${ }^{11}$ But what are the mechanisms?

McCarty and his colleagues have recently studied four patients with chronic destructive disease of the shoulder joint and evidence of hydroxyapatite crystal deposition, and their investigations have shed new light on the possible pathogenesis of crystal-induced arthropathies. ${ }^{12-14}$ All four 